\title{
AnALYSing Legitimation StRATEgIES In Relationship Advice Articles Of WOMEn's MAgAZINES
}

\author{
Reem Adib Lulu \\ Universiti Brunei Darussalam \\ reemadiblulu@gmail.com \\ Sharifah Nurul Huda Alkaff \\ Universiti Brunei Darussalam \\ sharifah.alkaff@ubd.edu.bn
}

\begin{abstract}
This study explores the strategies used to legitimate relationship advice articles in locally produced English language women's magazines from three different contexts, which are, Malaysia, the US, and two Middle Eastern countries (UAE and Egypt). Six women's magazines, two from each context, were chosen for this study. Sixty articles, ten from each magazine, from the relationship advice sections of each magazine were analysed using content analysis. Focus was given on the strategies used to legitimise these advice articles based on similar studies on the legitimisation of advice through the use of intertextuality and voices appearing in these texts. In addition, the study also investigated if there are differences in the strategies of legitimation used in these articles due to differences in the cultural norms in the three contexts. Findings revealed four legitimation strategies that were employed to construct advice in the texts we analysed, namely, 'Cross-Section of Real-Life', 'Appealing to Authorities', 'Celebrity Endorsement', and 'Popular Culture References'. Findings also revealed that the writers of sex and relationship articles in all three contexts have to carefully craft their texts to produce advice that is considered legitimate and can be accepted by their readers. Finally, the study showed that there appears to be a clear connection between the legitimation strategies used and the socio-cultural aspects of each society.
\end{abstract}

Keywords: Legitimation strategies, relationship advice Articles, women's magazines, cross-cultural analysis, popular culture

\section{INTRODUCTION}

Women's magazines were believed to first appear in Britain in the late $17^{\text {th }}$ century, catering to upper-class women who were literate and had time on their hands to indulge in reading. A century later, the readership of these publications was expanded to include middle-class women who were wives and mothers doing their domestic work (Talbot, 2010). According 
to Ceulemans and Fauconnier (1979: 39), women's magazines are distinguished from other media mainly because they are directed specifically towards women and are read primarily by women. They generally feature articles on fashion, beauty, health, fitness, lifestyle and relationships. Saner (2010) describes women's magazines as one of the most 'resilient' types of print media, with a vast array of titles on offer and enduring popularity. More importantly, like other forms of popular culture, they are often regarded as 'mirrors of social change', as stated by Ytre-Arne (2011, p. 249). Berns (1999) also states that they provide an interesting perspective on many issues and they introduce different social problems in greater detail than other types of mass media. This belief is shared by Caldas-Coulthard who stresses that women's magazines "are about being female and the problems of being female" (1996: 252). Thus, most women can relate to them as they directly address all matters related to them.

\section{REVIEW OF RELATED LITERATURE}

Studies on women's magazines often focus on beauty advertisements to investigate women's representation through textual or/and visual means (Brown \& Knight, 2015; Zhao \& Zhu, 2015). Other studies analyse the covers of magazines (Alagappar \& Selvaratnam, 2014; Conlin $\&$ Bissell, 2014). However, other areas of these magazines, such as relationship advice articles tend to be relatively under-researched in the literature on women's magazines. The relatively few studies in this area either explore the dominant themes of advice articles (Gill, 2010; Gupta et al., 2008; Machin \& Thornborrow, 2003), or they investigate the discourses found in these articles (Kauppien, 2013). Other studies investigate the linguistic constructions of advice articles (Lorenset, 2012; Erjavec, 2006).

Lorenset (2012), for example, analyses the visual and verbal aspects of love and sex articles in two online women's magazines. Her findings reveal that the writers aim to construct an intimate relationship with the readers to gain their trust and approval. They use strategies such as using direct address through the pronoun 'you', the use of informal language and presenting questions to the readers as a way of interaction. Erjavec (2006) explores textual devices that are used to construct female sexuality in advice articles in the Slovenian edition of Cosmopolitan. She proposes three discourse strategies, which are, prescriptive discourse, pseudo-scientific and pseudo-intimate. The prescriptive discourse is used to construct the theme of help and authority and the articles prescribe specific female sexual behaviour using textual devices, such as imperative mood, obligation modality, prescriptive vocabulary, and speech acts. The pseudo-scientific discourse, on the other hand, is used to construct and to legitimate the magazine's vision of normal sexuality, and it is expressed by using statistics and polls portraying cross-sections from real life and referring to experts or scientists. The pseudointimate discourse is used to create a sense of intimacy by using direct address to the readers, contact words, intimate vocabulary and paralanguage, among others.

Studies on relationship advice articles with a cross-cultural perspective tend to be particularly under-researched. Among these few studies are research conducted by Lulu and Alkaff $(2018,2019)$ and Machin and van Leeuwen $(2004,2003)$. This study is significant because as stated above, there is a relative dearth of cross-cultural studies on women's magazines presently. More cross-cultural studies such as this study are needed to gain better insights on the role of women's magazines in non-Western contexts as very little is currently known about them. More studies are also needed on home-grown magazines in a particular context as the majority of studies focus on international magazines. Analysing home-grown magazines would 
provide better insights and understanding on the values that they seek to promote concerning the predominant values or norms of the society it is set in rather than analysing local editions of international magazines. The latter probably reflects the ethos of the international publishing companies more than that of the local society, as asserted by Machin and Van Leeuwen's (2003) study. In this paper, the strategies used to legitimate relationship advice articles in Englishlanguage women's magazines are investigated. Data will be drawn from six English-language women's magazines from three contexts which are, Malaysia, the US, and the Middle East. Thus, the following research questions are proposed:

1. What are the strategies used to legitimate relationship advice articles in these magazines?

2. Are differences in the strategies of legitimation used in these articles due to differences in the cultural norms in the three contexts?

\section{METHODOLOGY}

This study looks at women's magazines in the following regions: Malaysia, United State (US), and Middle East (Egypt and UAE). Six women's magazines, two from each context, were selected for this study. All the magazines are home-grown English-language magazines with origins from the respective contexts. The two Malaysian women's magazines selected are Female and Her World. Female is Malaysia's top-selling lifestyle magazine and Her World is the first home-grown English language women's lifestyle magazine in Malaysia. The two Middle Eastern women's magazines selected are Ahlan (UAE) and What Women Want (Egypt). The former is the first home-grown English language lifestyle women's magazine to be established in the Middle East while the latter is one of the leading lifestyle English language women's magazine in Egypt. Two countries are selected rather than one, from the Middle East, because few locally produced English language women's magazines exist in the region. The majority of women's magazines available in the Middle East are either in the Arabic language or are local editions of international magazines. Although the Middle East context consists of two separate countries, Nydell (2012) states that most Middle Eastern countries share similar traits in terms of linguistic and cultural elements. The two US women's magazines chosen are Cosmopolitan and Marie Claire. Cosmopolitan is the biggest-selling women's magazine in the US and the world with 61 international editions around the world. Marie Claire is a close competitor of Cosmopolitan in terms of popularity, both in the US and overseas. The names of the magazines are represented in the findings section of this paper through the use of initials for brevity.

Sixty articles from the relationship advice sections of each magazine were selected for this study, ten from each magazine. All the articles were sourced online from the websites of the respective magazines. To analyse the data, legitimation strategies such as intertextuality and voices appearing in the articles were studied. According to van Leeuwen, (2008), using a legitimation strategy legitimates action through bringing attention to other voices or other sources of authority which may include experts, the law or tradition, or role models (pp. 106109). Fairclough (2003) uses the term authorization legitimation to refer to legitimation of advice. In analysing the texts for legitimation strategies, the whole text was examined rather than discrete elements within the text. The analysis of data was conducted using content analysis to identify the legitimation strategies as identified by Erjavec (2006) as well as to unearth new strategies based on the examination of the texts. 


\section{FINDINGS}

The findings reveal four legitimation strategies that are employed to construct advice in the texts we analysed. These four strategies are: 'Cross-Section of Real-Life', 'Appealing to Authorities', 'Celebrity Endorsement', and 'Popular Culture References'. The first two strategies are adopted from Erjavec's (2006) study, while the other two are derived from the analysis of our data. Erjavec (2006) discusses the first two categories within what she terms the 'pseudoscientific discourse' that is used to construct and legitimate the vision of 'normal sexuality' in the Slovenian edition of Cosmopolitan. Unlike Erjavec's study, this study investigates voices used in the texts rather than types of discourses. The frequency of each strategy occurring in each cultural context is shown in Table 1 below.

\section{Table 1: Legitimation strategies and their frequencies in relationship advice articles}

\begin{tabular}{|c|c|c|c|}
\hline Legitimation strategies & US & Malaysia & $\begin{array}{l}\text { Middle } \\
\text { East }\end{array}$ \\
\hline \multicolumn{4}{|l|}{ Cross-Sections from Real-Life } \\
\hline Selective situations from real-life problems & 2 & 0 & 0 \\
\hline Testimonies and confessions & 50 & 29 & 8 \\
\hline Detailed narratives & 5 & 4 & 8 \\
\hline Personal experience of the writer & 14 & 1 & 9 \\
\hline An experience of the writer's close friend or acquaintance & 7 & 1 & 3 \\
\hline Hypothetical story of the reader & 0 & 0 & 3 \\
\hline \multicolumn{4}{|l|}{ Appealing to Authorities } \\
\hline \multicolumn{4}{|l|}{ Appealing to experts: } \\
\hline (i) Anonymous experts & 2 & 2 & 11 \\
\hline (ii) Named experts & 20 & 13 & 16 \\
\hline \multicolumn{4}{|l|}{ Appealing to studies and publications: } \\
\hline $\begin{array}{l}\text { (i) Studies/ researches (without sourcing or naming the } \\
\text { study) }\end{array}$ & 1 & 1 & 0 \\
\hline $\begin{array}{l}\text { (ii) Findings of studies/projects/reports/etc (with } \\
\text { information about the name or the source of the study) }\end{array}$ & 3 & 6 & 3 \\
\hline Self-help books & 2 & 0 & 1 \\
\hline Celebrity Endorsement & 10 & 8 & 15 \\
\hline *Well-known persons & 1 & 1 & 2 \\
\hline Popular Culture References & 6 & 2 & 1 \\
\hline
\end{tabular}

Each strategy that is used in this study is explained in detail in the following sub-sections:

- Cross-Sections from Real Life According to Erjavec (2006), 'Cross-sections from Real Life' refers to narratives and shared experiences the writer presents in the text as a form of providing evidence which helps to create a sense of reality, credibility and authenticity (p.51). The advice texts in this study provide different forms of cross-sections from real life to legitimate 
the given advice, and to create a sense of solidarity by making the readers believe that other people, specifically women, share or face similar problematic situations. Hence, it is possible to solve their problems if they follow the advice provided in the text. Unlike Erjavec's study in which this particular strategy is discussed generally as a form of discourse, the data analysis of this present study shows six distinct forms of the same strategy; probably because Erjavec only analyses the Slovenian edition of Cosmopolitan, unlike this study which looks at three different contexts. Hence, it is expected that the data in this study will show variations within one strategy. These six forms are as follows:

(i) Selective situations from real-life problems

In this form, different types of problems are presented in the same text but through different situations or different questions which require specific solutions. Women in these articles who face problems have no voice in offering advice; they are only allowed to share problems they face in their lives. Hence, it is the writer's role to provide his/ her help. This form is found in two articles in the US data, specifically in Cosmopolitan, but none in the Middle Eastern and the Malaysian data.

\section{(ii) Testimonies and confessions}

The writer displays different opinions, testimonies or confessions of women who have experienced a specific situation. These confessions are mainly written in quotations and information about these women are provided which may include their name, age, place of residence and career. Verbs of testimonies include 'admit', 'confess', and 'say'. As shown in Table 1 above, this form of real-life endorsement is more predominant in the US data than in the Malaysian or Middle Eastern ones. The findings reveal that confessions from different people appear in the same text in the US data. For example, in the article "How to Handle Your Best Friend Getting Pregnant" (CP) different confessions appear in the text, such as: "When my friend got pregnant, I felt so betrayed," confesses Maddie R., 27, from Boston; and "When my best friend at work got pregnant, I wanted to sob," says Erica G., 30, from Binghamton, New York. It is also noted that all names and places which are found in the US data are local.

On the other hand, it is noted that the Malaysian writers tend to appeal to readers' personal opinions about specific issues, for example, in the article "Can a Woman and Man JUST Be Close Friends?" (F), different opinions or answers are stated by female readers on Facebook for the following two questions "Can a woman and a man JUST be close friends?", and "what are the good and bad parts about having a dude as y our BFF." Their answers are directly quoted in the text, such as "Yes for women; no for men." Christy," and, "Yes, but something might secretly happen in between and both sides might not admit it." - Siti. It is observed that the readers' names are very carefully selected; Muslim and non-Muslim names are found. This could be viewed as a way to not just demonstrate the diversity of the country but also as a way to impress on readers that the confessions and testimonies come from a wide cross-section of the society, thus emphasising the legitimacy of these opinions.

On the other hand, unlike in the US and the Malaysian data, it is found that the Middle Eastern writers refrain from using testimonies and confessions in advice articles as very few examples are found in the Middle Eastern data. 
(iii) Detailed narratives

Unlike the previous form (Testimonies and Confessions), narratives of women who faced specific problematic issues and the ways they solved problems are presented in detail and not through brief confessions or opinions. The narrative may include information about a woman's name, age, career, and place of residence/work. Different narratives can appear in the same text, as found in the US data. For example, in the article "Are Contracts the Key to Long-Term Relationships?" (MC) two narratives appear in the same text about two women who both faced problems that were a result of their live-in relationship with their boyfriends. The text shows their problems in detail and the solution they followed, which is, drafting a cohabitation agreement. The two women's opinions are provided through direct quotations in the text.

This style of narrative is rare in the Malaysian data since it is found in only two articles, which are, "Juicy Read: It's Just Casual Sex..." (F), and "Would You Snoop on Your Boyfriend's Phone While He's Asleep?" (HW), with two examples in each article. Unlike the US data where names of women in narratives are always local, the writers in the Malaysian articles carefully select names of women in narratives which deal with sensitive topics. For example, in the former article, the writer selected two non-Muslim names, Kim and Pamela. This can be seen as a strategy to avoid a backlash in raising issues that are deemed immoral in a mainly Muslim society like Malaysia.

The findings also reveal that this type of narratives is more prevalent in the Middle Eastern advice articles than in the US and the Malaysian data. Most of the narratives are discussed in great detail in the Middle Eastern texts. The findings also reveal that all the names that appear in the narratives are not local despite the local setting. For example, the article "Are You A Screen Siren?" (AH) displays the narrative example of a 31-year old Romanian girl called Daniella Corneliu, who lives in Dubai and works as a receptionist at a hotel. Her problem is that she has had a hard time meeting interesting, new people. She solved her problem by trying Tinder, as explained in her quotation "It's entertaining... but I've actually met someone who could be a friend or something more, I'm still figuring it out..."

(iv) Personal experience of the writer

In this form, the writer confesses or narrates about a personal experience he/she had experienced or witnessed. This form is more common in the US and the Middle Eastern data than in the Malaysian one. It is found in only one article in the Malaysian data. The writer presents his/her personal experience by the personal pronoun ' $\mathrm{I}$ ' or the possessive determiner 'my'. For example, in the article "When Your Ex Gets EngagedThe Ex Factor" (AH), the writer confessed about the problem she faced: "when I learnt that my ex-boyfriend had got engaged... When the initial sucker punch of surprise, hurt and fleeting regret had died down, I just felt like a failure...", and the personal solution she adopted: "But I've learnt to embrace it. I know they weren't right for me, and clearly during our time together, I managed to mould them into excellent husbands - albeit for other people."

\section{(v) An experience of the writer's close friend or acquaintance}

Here, the writer presents an example of a woman he/she knows. This woman can be the writer's close friend or an acquaintance. This happens in seven articles in the US data, in three articles in the Middle Eastern data, and once in the Malaysian data. An 
example of the writer's friend is featured in the article "Breaking the Trust: Snooping on Your Guy" (MC): "My friend Elizabeth told me that she once searched an ex's porn site history...". Another example of an acquaintance of the writer appears in the article "Are You on the Verge of a Public Meltdown?" (CP): "Another acquaintance posted court documentation that she changed her son's last name from the father's to her maiden name, aiming to embarrass her son's father...".

(vi) Hypothetical story of the reader

In this form, the writer addresses the reader directly by using the pronoun 'you' to introduce a specific problematic situation in the text. In this sense, the reader is asked to picture herself in a hypothetical situation by imagining the scenario of the problem. This happens in three articles in the Middle Eastern data, but none in the US and the Malaysian ones. The article "Marital Porn_Is Watching Porn the Real Deal Breaker?" (WW), for example, presents the problem of having a husband who is secretly watching porn through the pronoun 'you', and the possessive pronoun 'your'. The writer uses the pronoun (he) to refer to the husband and to narrate the story in details: "...The house is quiet and dark and everyone is sleeping peacefully. Well, everyone but him. He reaches for his laptop and tip toes to the bathroom... Your husband never does anything quietly... $\underline{\mathrm{He}}$ stretches out his finger eager to type www... You crawl out of bed ready to pounce... $\underline{\text { He forgets }}$ to press the mute button and the noise of passion blasts... You listen to him...".

- Appealing to Authorities

The writers of the advice articles studied appeal to the authorities to legitimate and construct the validity of their advice. The findings reveal that there are two categories of external authorities appearing in the articles, which are, 'appealing to experts' and 'appealing to studies and publications'. These two types are clearly demonstrated in detail, as follows:

1. Appealing to experts

Two different forms are found under this category, which is, referring to anonymous experts and referring to named experts, as discussed below in detail:

\section{(i)_Anonymous experts}

Within this form, two distinct types are found here. First, there is an appeal to authorities by referring to experts in general such as 'experts agree', 'experts say', 'according to experts', and 'experts found'. Only a few examples are found in the US and the Malaysian data but, there are six references in the Middle Eastern data. In the second type, the expertise of the 'experts' is identified, such as 'relationship experts', 'relationship coaches', and 'psychologists'. There is one reference to this type in both the US and the Malaysian data, and five references in the Middle Eastern data.

\section{(ii) Named experts}

In this form, information about the experts are provided such as name, place of work, publications produced by them and links to their website. Among the 60 articles studied, there are 49 references to these experts (20 in the US data, 13 in the Malaysian 
data, and 16 in the Middle Eastern data). The writers appeal to named experts to explain or clarify specific information or facts, present their findings that relate to a specific solution or offer their suggestions to solve a specific problem.

It is found that references to experts are often presented in direct quotations but most of these quotations are less than two lines. However, in a few articles in the Middle Eastern data, specifically in Ahlan, the quotations can sometimes be quite lengthy. Ahlan appears to depend heavily on the voice of external authorities or experts rather than the voice of the writers. The Ahlan writers also refer to the same expert throughout the same text. For example, in the article "How Not to Let Fights Ruin Your Relationship" (AH), a long quotation is presented from the love expert Shasta Townsend: "winning an argument can mean you both move forward together feeling stronger... It is a great way to create bitterness, resentment and, of course, tension". The writer again refers to this expert by referring to her suggestions as cited in her blog post, which is written in three paragraphs. The writer then appeals to another expert in the same text, Jeyla Shikhlinskaya, a licensed family and relationship therapist, with a long quote as well. In the US data, the experts are all Western-based experts, believed to be mostly American. However, in the Malaysian and Middle Eastern data, they are a mix of Western and non-Western experts.

\section{Appealing to studies and publications:}

Three points are observed under this type, which is discussed as follows:

(i) Studies or researches are mentioned in general without any information about the name of the study and its source. There is one reference to this form in the US and the Malaysian data, but none in the Middle Eastern ones. For example, "Research shows a long-distance relationship has a better chance of working if there is an end date in sight..." (CP).

(ii) Findings of studies, projects, reports, polls or surveys are presented, with information about the name or the source of the study, which may include a link to the website or blog of the study. There are three references to this form in the US and the Middle Eastern data and six references in the Malaysian data. For example, in the article "Are Contracts the Key to Long-Term Relationships?" (MC) the writer appeals to a report and a poll with statistics in their findings: "...74 percent of U.S. women will live with a partner before 30, according to a 2013 report from the National Center for Health Statistics, with many bringing their own assets to the table... Nearly 40 percent of divorce lawyers say they've noticed an increase in these agreements, according to a recent poll by the American Academy of Matrimonial Lawyers".

(iii) Self-help books are presented in the text, which are mainly written by the writer of the text. This is found in two articles in the US data and in one article in the Middle Eastern data. In the article, "Six Lies People Tell You about Being Single" (CP), for example, the writer Sara Eckel refers to her book 'It's Not You: 27 (Wrong) Reasons You're Single', in which she presents some of her findings in the text.

- Celebrity Endorsement

In this strategy, writers of relationship articles refer to examples from celebrities to show readers that celebrities also share the same problems. They also aim to present 
problems as real ones. It is found that there are 10 references to celebrities in the US data; all are American actors/actresses or singers. It is also found that there are eight references to celebrities in the Malaysian data. However, unlike the US data, these celebrities are not local. They are mainly American actors/actress, with a few Singaporean and Australian celebrities as well.

It is also noted that about 15 references to celebrities are found in the Middle Eastern data. Similar to the Malaysian data, these celebrities are not local as they are mainly American actors/actresses. In the article "How to Avoid Getting Clooney-ed" $(\mathrm{AH})$, for example, the writer refers to the American actor, George Clooney, in the headline, and in the text, she again gives an example of this celebrity on how he was not a commitment type of man since he told his exes from the start he does not want a big commitment or marriage: "We saw it happen to Stacy Keibler when she started dating the inimitable George Clooney... we wanted to shout out to her -Didn't you see what happened to Elisabetta Canalis before you? And Renee Zellweger and the other string of beautiful, financially independent, lovely women that George Clooney dated before you? They wanted children... some form of commitment - but he didn't...". This particular example of celebrity references functions to show that this problem is a real one and to reassure readers that beautiful, famous, independent, and successful women also have similar problems.

It is worth noting that the writers may also refer to well-known persons who are not entertainment celebrities such as novelists or writers. This is found in one article in the US data, which is, "Why Sexting Is Good for You" (CP) where there is a reference to the feminist Simone de Beauvoir and the Irish novelist James Joyce, aiming to show that well-known persons also 'sext' with their lovers, for instance, "Take James Joyce, ...", "My sweet little whorish Nora...", "I did as you told me ... and pulled myself off twice when I read your letter." There is also one reference to a well-known person in the Malaysian data, specifically, in the article "Would You Snoop on Your Boyfriend's Phone While He's Asleep?" (HW). The writer refers to a Singaporean writer and columnist at the Sunday Times, Sumiko Tan, to show that well-known women also snoop on their partners: "The Sunday Times columnist Sumiko Tan revealed that she frequently checks her husband's SMSes, e-mails and letters - with his permission...". Two references to wellknown people are also found in the Middle Eastern data; there is a reference to Sean Rad, Tinder's creator and founder, in the article "Are You a Screen Siren?" (AH), and to Mark Zuckerberg, the founder of Facebook, in the article "Update Status, Love Reunited..." (AH).

\section{- Popular Culture References}

In this strategy, the writers refer to entertainment sources which include movies, TV series, and popular books. They use such sources, perhaps, to reduce the complexity of the problem and to make the article more interesting. Six references to this form are found in the US data, which include American movies, and TV sitcoms. For example, there is a reference to the American sitcom 'How I Met Your Mother' in the article "10 Ways to Ruin a First Data" (MC): "There's a beautiful moment in How I Met Your Mother where the protagonist, Ted, has been on two dates and is trying to choose between those two women... In his mind that makes them equal. You don't have to split the bill on every date, but at the very least make a kind gesture of offering to pay.". Other references in other articles include 'Wedding Crashers', (American romantic comedy film), 'Sex and the City', 'The 
Mindy Project', 'New Girl', (American TV comedy series) and 'Girl', (American TV drama series).

In both the Malaysian and the Middle Eastern data, there are Western, non-local references to this form: there is one reference to the popular novel 'Fifty Shades of Grey' in the article "10 Things You Must Try for Mind-Blowing Sex" (HW) and another reference to the same novel in the article "5 Naughty Games to Sizzle Things Up in $\operatorname{Bed}^{\prime \prime}(\mathrm{F})$, while there is one reference to the famous ancient Indian text 'Kama Sutra' in the Middle Eastern data in the article "Marital Porn_ Is Watching Porn the Real Deal Breaker?" (WW).

\section{DISCUSSION}

The analysis above draws attention to four legitimation strategies. In relation to the first legitimation strategy, Cross-Section from Real-Life, which has six distinct forms, it is found that forms that are preferred in the US data are: 'testimonies and confessions', 'personal experience of the writer', and 'experience of the writer's close friend or acquaintance'. This may convey the idea that the writers of the US magazines try to show their readers that other women, like the readers and the writers themselves, belong to the same community as they share the same problems. In the Middle Eastern data, forms that are preferred include 'detailed narratives' and 'personal experience of the writer'. Perhaps one of the reasons Middle Eastern writers prefer the use of 'detailed narratives', for example, is because as explained by Kaplan (1966) in his canonical work on contrastive rhetoric, cultural thought patterns and first language can influence the writings of second language users. The writers of the women's magazines in the Middle Eastern context appear to be non-native English speakers, and hence, their thoughts may be expressed in a series of ideas as Arabic is less direct and linear than English. Regarding the form 'personal experience of the writer', which is also a popular legitimation strategy in the Middle Eastern data, it can be argued that perhaps this is a strategy to avoid involving local names in relationship issues. Even though the writers themselves appear to be from the same society, they are perhaps more willing to share their experiences than the readers. In the same vein, the Middle Eastern writers may also use 'hypothetical story of the reader' to avoid mentioning local names when talking about sensitive sexual and relationship issues, such as a husband who likes to watch porn or a husband who is too friendly with his wife's best friend. The writer used such forms so that readers can picture themselves in the situation and at the same time, references to local names are avoided as the stories are considered 'hypothetical'. In the same way, the form 'testimonies and confession' is rarely found in the Middle Eastern data as this form is probably viewed as too risqué to present in a conservative society.

The Malaysian data, on the other hand, prefers the form of 'confessions and testimonies' over other forms. However, in the Malaysian magazines, this form is normally shown as presenting readers' personal opinions about specific issues which become part of the solutions provided to readers, and also the opinions of Malaysian men on selected issues related to women. This is probably done to show the interactive connection between the readers and the writers and to show that such solutions are presented from real life rather than by the writer herself. It can also be viewed as a less controversial way to present any 'confessions', for example, as more than one opinion will be presented. In addition, it is also noted that only the first names and never the full names of the readers are provided. Forms such as detailed narratives are not common in the Malaysian data because the texts are often brief and presented in a bullet point format. 
In relation to the first strategy, 'Cross Sections from Real Life', the names of women in the data analysed are very carefully selected, as stated earlier. In the US data, all names of women are local which gives an implicit message that readers should consider the women mentioned in the texts as "one of them" and they should thus, follow their solutions. In the Malaysian data, the writers used names from different cultural backgrounds, perhaps as a way to show that their readers come from different ethnic groups in Malaysia, thus indicating that the advice given applies to all, regardless of ethnicity. However, the writers are often perceived as trying to avoid getting drawn in potentially controversial issues through excluding Muslim names from the examples provided in the texts, such as selecting non-Muslim names to provide examples for girls who have experienced casual sex, given the taboo on Muslims having sex outside of marriage. In the Middle Eastern data, all women's names that appear in the narratives are not locals. This could be a reflection of the sensitiveness of discussing social topics pertaining to women and relationships in the Middle Eastern culture. Although the Malaysian and the Middle Eastern data avoid selecting Muslim names in their examples, it could be stated that the Middle Eastern data are stricter in terms of names as they select non-local names as well as identifying them explicitly as non-locals in all their examples as the topic of relationship in general, is considered very sensitive to be discussed, unlike the Malaysian data where the avoidance of Muslim names only occurs when discussing risqué topics such as casual sex. This illustrates the fact that although both are mainly Muslim societies, the degree of conservatism varies considerably between these societies.

In relation to the second legitimation strategy, 'Appealing to Authorities', the analysis shows that the writers in the three contexts analysed appeal to 'named experts' more than 'anonymous experts'. Perhaps they want the advice articles to look more authentic and credible and hence the readers would view their information as incontrovertibly true. They also appeal to 'named studies, projects, reports, polls or surveys' more than 'anonymous studies or research'. The reason for using more named studies is similar to the reason for using more named experts, that is, the writers of advice texts are aware about conveying messages of truthfulness, validity and authenticity in their texts as a means of legitimation. In contrast, 'anonymous experts' appears to be used more often in the Middle Eastern data as perhaps, the writers refer to local Middle Eastern experts for advice but due to the climate of conservatism, they must not be named.

In general, the process of selecting voices in these articles is more complicated than expected since the writers not only carefully select names of women found in examples or narratives, as mentioned earlier, but they also very carefully select names and sources of external authorities, including experts and studies. The majority of experts and studies presented in the US data are Americans as the writers aim to show their readers examples of studies conducted in their society and hence they can be applied to their own problems and to present the local expert as someone the reader can trust or contact when facing any problem. On the contrary, experts and studies presented in the Malaysian and the Middle Eastern data are all non-local, mainly Western-based. This is because it is not common to find local experts in the domain of sex and relationship in these societies, or to avoid potential socio-cultural conflicts in a conservative society regarding relationship topics, specifically in the Middle Eastern context, or they may adopt Western experts as role models due to the liberal ideology of this society that would allow greater freedom to discuss matters on sex and relationships.

It is worth discussing that in the first two strategies, 'Cross-Sections of Real-Life' and 'Appealing to Authorities', the writers mainly represent the words of ordinary women in 
the form of narratives or examples, or the voice of experts, mainly in direct quotations. Most of these direct quotations are presented in less than two lines, except in a few articles in the Middle Eastern data where quotations can exceed this number of lines, as mentioned earlier. This is because the US writers refer to different experts and confessions within the same article, unlike the Middle Eastern articles which mainly refer to the same expert throughout the text. Another reason is that the Middle Eastern writers try to eliminate their voices when it comes to discussing sex and relationship issues, which means that the voices of external authorities are greater than the voices of the writers. In the Malaysian data, however, direct quotations are mainly found in articles that require readers' personal opinions about specific issues, and the opinions of Malaysian men on selected issues related to women. This fact means that the writers in such articles depend on external voices which are stated in direct quotations. In addition, it is perceived that, direct quotations are used in the Malaysian data as a technique to eliminate the writers' opinions in relation to issues which are deemed as sensitive in a conservative society, for example, the issue of casual sex, as discussed earlier.

In the third strategy, 'Celebrity Endorsement', the writers use the voices of entertainment celebrities as well as other well-known people such as writers to present problems as real ones. The writers may aim to show young readers that they are up to date with news of celebrities and famous people, and hence they belong to the same cultural and age group. This adds a sense of credibility and reliability to the text. The writers prefer to use examples from entertainment celebrities rather than other famous women in the field of politics or economics, probably to make the articles more attractive and enjoyable since they are online articles. That is, the content of these online articles is expected to entertain and offer light reading. The examples of celebrities which are found in these articles are mainly within the domain of love and relationship as these articles deal almost exclusively with such issues. The situations arising from such examples mainly occur in the personal life of these celebrities rather than in their professional work. These situations include breaking up, snooping on boyfriend, being a friend with the boyfriend after breaking up, and others.

An interesting finding in relation to the celebrities that are named and referred to in this strategy is that almost all these people are Western celebrities, with the exception of a single reference to a Singaporean celebrity in a Malaysian article. This clearly reflects the fact that these magazines, regardless of the context, subscribe heavily to Western dominant terms of reference which is illustrated by the almost exclusive use of Hollywood and Western celebrities in this strategy. This could also be a reflection of the globalisation of popular culture which is mainly dominated by celebrities from the West. The use of Western celebrities in the Malaysian and Middle Eastern data can also be viewed as a means to avoid being embroiled in a controversy with the authorities if local celebrities are used as examples in relation to relationship issues. The fact that these magazines are English language publications may also account for the fact why references to Western or Hollywood celebrities are preferred.

In the fourth strategy, 'Popular Culture References', the writers refer to well-known entertainment sources to legitimate advice articles. Similar to the purpose of using celebrity endorsement, the writers may aim to present the content of online articles as light reading. In other words, the 'Popular Culture References' strategy helps to amuse the readers and grab their attention towards the content of the articles. It also helps to arouse readers' emotions and to appeal to their fantasy and imagination. In the US data, the entertainment sources cited are all home-grown and local which may meet the expectation of the target readers. However, there are non-local references to this strategy in both the Malaysian and the Middle Eastern 
data, for example, the Malaysian data refers to the popular American novel 'Fifty Shades of Grey' while the Middle Eastern data refers to the famous classical Indian sex-guide, 'Kama Sutra'. As with the 'Celebrity Endorsement' strategy, in both non-Western contexts, the entertainment sources cited are all Western-based. Even though the Kama Sutra is an ancient Indian text, it has generally been appropriated by Western culture over the years. Again, as in the previous strategy, the dominance of Western-based references is due to the globalisation of culture in which Western popular culture reigns supreme. In addition, as the Malaysian and Middle Eastern magazines are English language magazines, hence, it is expected that Western references would dominate the texts.

\section{CONCLUSION}

This cross-cultural study on the legitimation strategies used by writers of relationship advice articles in women's magazines in three different cultural contexts reveals that these writers have to carefully craft their texts in order to produce advice that is considered legitimate and can be accepted by their readers. It demonstrates that a fair amount of creativity is needed in order to produce advice that not only appears credible but can entertain their readers so that they can continue reading and even consider the advice given by these writers. This study has also shown that there is a clear connection between the legitimation strategies used and the socio-cultural aspects of each society. Further research can be conducted on non-English language women's magazines to identify the legitimation strategies used by the writers of advice articles and to compare the findings with those found in this present study.

\section{REFERENCES}

Alagappar, P. N., \& Selvaratnam, L. (2014). Analysis of a Malaysian edition of foreign magazines in portraying women's issue. International Postgraduate Business Journal (IPBJ), $6(1), 49-67$.

Berns, N. (1999). "My problem and how I solved it": Domestic violence in women's magazines. The Midwest Sociological Society, 40 (1), 85-108.

Brown, A., \& Knight, T. (2015). Shifts in media images of women appearance and social status from 1960 to 2010: A content analysis of beauty advertisements in two Australian magazines. Journal of Aging Studies, 35, 74-83.

Caldas-Coulthard, C. R. (1996). 'Women who pay for sex. And enjoy it': Transgression versus morality in women's magazines. In C. R. Caldas-Coulthard, \& M. Coulthard (Eds.), Text and practice: reading in critical discourse analysis. London: Routledge.

Ceulemans, M., \& Fauconnier, G. (1979). Mass media: The image, role, and social conditions of women. A collection and analysis of research materials. Catholic University of Leuven, the Department of Communication Science. Paris: UNESCO.

Conlin, L., \& Bissell, K. (2014). Beauty ideals in the checkout aisle: Health-related messages in women's fashion and fitness magazines. Journal of Magazine $\mathcal{E}$ New Media Research, 15(2), 1-19.

Erjavec, K. (2006). How to have good sex? The Cosmopolitan's construction common sense and consensual view of sexuality. Medijska istraživanja, 12 (2), 41-62.

Fairclough, N. (2003). Analysing discourse. Textual analysis for social research. London and New York: Routledge. 
Gill, R. (2010). Mediated intimacy and postfeminism: a discourse analytic examination of sex and relationships. Discourse and Communication, 3, 345-369.

Gupta, A. E., Zimmerman, T.S., \& Fruhauf, C. A. (2008). Relationship advice in the top selling women's magazine, Cosmopolitan: A content analysis. Journal of Couple E Relationship Therapy: Innovations in Clinical and Educational Interventions, 7(3), 248-266.

Kaplan, R. (1966). Cultural thought patterns in inter-cultural education. Language Learning,16 (1), 1-20.

Kauppinen, K. (2013). At an intersection of postfeminism and neoliberalism: A discourse analytical view of an international women's magazine. CADAAD Journal, 7 (1), 82-99.

Lorenset, C. C. (2012). Visual and lexicogrammatical analysis of websites of women's magazines. The International Gender and Language Association. Universidade Federal de Santa Catarina - UFSC.

Machin, D., \& Thornborrow, J. (2003). Branding and discourse: the case of Cosmopolitan. Discourse \& Society, 14 (4), 453-471.

Machin, D., \& Van Leeuwen, T. (2004). Global media: Generic homogeneity and discursive diversity. Continuum Journal of Media and Cultural Studies, 18 (1), 99-120.

Machin, D., \& Van Leeuwen, T. (2003). Global schemas and local discourses in Cosmopolitan. Journal of Sociolinguistics. Journal of Sociolinguistics, 7 (4), 493-512.

Nydell, M. (2012). Understanding Arabs: A contemporary guide to Arab society (5th ed.). Boston: Nicholas Brealey Publishing.

Lulu, R. A. \& Alkaff, S. N. H (2018). Of lust and love: A cross-cultural study of sex and relationship advice articles in women's magazines. Journal of Sexuality and Culture, 22 (2), 479-496.

Lulu, R.A. \& Alkaff, S.N. H. (2019). A cross-cultural study of persuasive strategies in relationship advice articles in women's magazines. GEMA Online, Journal of Language Studies 19, (2), 15-32.

Saner, E. (2010) 'Women's magazine sector is bullish about the future', The Guardian, 11 October, https://www.theguardian.com/media/2010/oct/11/womens-magazines-bullishfuture (December 2017).

Talbot, M. (2010). Language and gender (2nd ed.). Cambridge, UK: Polity.

Van Leeuwen, T. (2008). Discourse and practice: New tools for critical analysis. Oxford: Oxford University Press.

Ytre-Arne, B. (2011). Women's magazines and the public sphere. European Journal of Communication, 26 (3), 247-261.

Zhao, M., \& Zhu, Y. (2015). A content analysis of advertisements in women's fashion magazines in China. Proceedings of the 17th International Academic Conference, (pp. 632-632). Vienna: International Institute of Social and Economic Sciences. 